\title{
The Use of Raman Fluorescence Technology to Evaluate the Effectiveness of Remineralization of Solid Tooth Tissue
}

\author{
Prikule DV, Alexandrov MT*, Kukushkin VI, Pashkov EP, Achmedov AN and Namiot ED \\ Scientific and Clinical Center for the Rehabilitation of Women's Health, Russia
}

*Corresponding author: Alexandrov MT, Scientific and Clinical Center for the

Rehabilitation of Women's Health, Russia.

Received Date: March 04, 2019

Published Date: March 28, 2019

\section{Introduction}

Tooth enamel is the most mineralized tissue of the body. Composition - 96 wt. \% inorganic matter and 4 wt. \% of organic matter and water. Inorganic the substance mainly consists of calcium phosphate associated with hydroxyapatite, the chemical formula of which is [Ca10 (PO4) $6(\mathrm{OH}) 2$ ]. The presence of hydroxyapatite is confirmed by the presence of its spectral bands in the hard tissues of the tooth [1]. It is believed that Raman spectroscopy allows you to objectively evaluate spectral bands associated with specific chemical structures of tooth hard tissues $[2,3]$. So currently this technology can be considered preferable in the study of remineralization of teeth [4-10]. The purpose of our study is to determine the effectiveness of the Raman-fluorescent method of diagnosing the remineralization of hard tooth tissues using demineralizing pastes, gel, suspension and rinse aid.

\section{Materials and Methods}

In this pre-clinical in vitro study on 25 model test objects of teeth (incisors of the lower jaws), removed for clinical reasons, Raman fluorescence spectroscopy was performed (after their hygienic cleaning professional toothpaste) using the Inspector $\mathrm{M}$ laser hardware-software complex with a probe radiation waves with the length of $532 \mathrm{~nm} .5$ of the model test objects of teeth are placed in a $10 \%$ suspension of Nano-HAP (Ca, Mg, Zn) for 1 min for 21 days (the period recommended for demineralizing therapy); 5 test objects were cleaned with paste containing Nano-HAP (Ca, $\mathrm{Mg}, \mathrm{Zn}$ ) daily for 21 days in the morning and in the evening; A gel containing nanogap in a complex with soluble calcium in one drug was inflicted (once a day) on 5 test objects for 21 days; 5 test objects were processed with rinse for 21 day daily; control group - 5 test objects that were in deionized water for 21 days. Measurements of the Raman-fluorescent characteristics of tooth hard tissues were carried out after 21 days. Repeated measurements in all groups were performed after 14 days to determine the duration of the preservation of the mineralization effect of tooth enamel. AIC "Inspector $\mathrm{M}$ " is designed to measure Raman spectra or photoluminescence spectra of liquids, solids, powders and gels. The device consists of a laser radiation source, a system for collecting, filtering and analyzing the scattered radiation, equipped with a lownoise multi-channel detector - analyzer (CCD line) to measure the amplitude and spectral characteristics of the scattered radiation [11-13].

The spectral range of the complex covers the molecular region of the fluctuations in organic and inorganic substances which allows to measure within several seconds the Raman or fluorescence spectrum of the object under study, determine the spectral position and relative intensities of Raman and fluorescent spectral lines. The software of this device facilitates the qualitative and quantitative analysis of the spectra obtained and the identification of the substance, comparing the resulting spectrum with the reference [3]. With the use of AIC "InSpectr M" the test objects were subjected to non-destructive effects of low-intensity laser radiation in the visible range $(532 \mathrm{~nm})$. The results of the study were processed online, using during the work the presented hardware-software complex. The measurements were carried out contact-stable and perpendicular to the surface of the tooth enamel.

For a quantitative assessment of the spectral intensity of Raman radiation (in relative units $\mathrm{M}$ cf.) indicators were measured in the maximum and minimum of its power and indicators of fluorescence intensity ( $\mathrm{M}$ cf.). Registration and software processing of results of the research took 2 min. Results (M cf.) studies are presented in the form of figures and tables. The results were processed by standard statistical methods using the standard block of statistical programs Microsoft Excel (2007) and SPSS Statistics 23 based on 
criteria Kolmogorov - Smirnova and Shapiro - Wilk. To describe quantitative traits, the average value and standard deviation of the trait M, standard deviation (m) were calculated. Values are in the form of $\mathrm{M} \pm \mathrm{m}$

\section{Results and Discussion}

Raman-fluorescent enamel characteristics of tooth hard tissues in the control group are presented in Figure 1. (see on the insert). Indicators of the degree of mineralization of tooth enamel by their intensity did not change in the dynamics of observation and averaged 324 rel. units (the differences are not reliable). Ramanfluorescent diagnostics of the enamel of the central lower incisors before and after demineralizing therapy is shown in Figure 1 (see on the inset). From Figure 1, a it follows that after the action of the demineralizing paste, the Raman hydroxyapatite intensity increased on the average of 1511 rel. units and decreased after 14 days of extra exposure in deionized water at 711 relative units but remained above baseline by 800 rel. units. From Figure 1, it follows that after the action of the demineralizing suspension, the Raman intensity hydroxyapatite increased by an average of 1337 rel. units and decreased after a 14-day additional extracts being held in deionized water for 932 rel. unit, but remained above baseline by 355 rel. units From Table 1, it follows that after the action of the demineralizing suspension, the Raman hydroxyapatite intensity increased by an average of 1176 rel. units and decreased after a 14-day additional exposure in deionized water by 942 rel. units, but remained above the baseline by 234 rel. units From Figure 1, it follows that after the action of the demineralizing suspension, the Raman hydroxyapatite intensity increased by an average of 621 rel. units and decreased after 14 days of additional exposure in deionized water by 376 rel. unit, but remained above baseline by 245 rel.

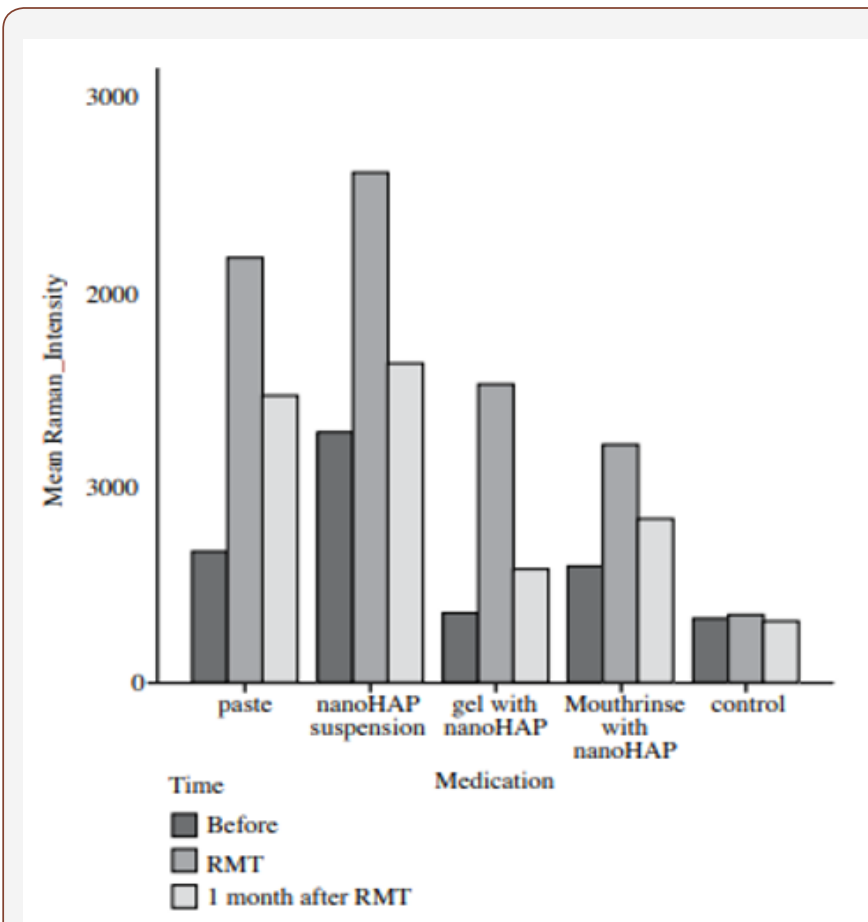

Figure 1: Raman-fluorescent characteristics of the effectiveness of various demineralizing drugs.

Table 1: The average spectral characteristics of enamel before and after remineralization therapy.

\begin{tabular}{|c|c|c|c|}
\hline Indicator & $\begin{array}{c}\text { Raman Signal Intensity / Wave- } \\
\text { length at Maximum }\end{array}$ & $\begin{array}{c}\text { Raman Signal Intensity / Wave- } \\
\text { length at Maximum }\end{array}$ & $\begin{array}{l}\text { Raman Signal Intensity / Wave- } \\
\text { length at Maximum }\end{array}$ \\
\hline $\begin{array}{l}\text { Enamel after a course of cleaning } \\
\text { paste with nano-HAP }\end{array}$ & $y=671 \pm 309, x=963 \mathrm{~cm}^{-1}$ & $y=2182 \pm 309, x=963 \mathrm{~cm}^{-1}$ & $y=1471 \pm 531, x=963 \mathrm{~cm}^{-1}$ \\
\hline $\begin{array}{l}\text { Enamel after a course of suspen- } \\
\text { sion of } 10 \% \text { with nano-HAP }\end{array}$ & $y=1280 \pm 898, x=963 \mathrm{~cm}^{-1}$ & $\mathrm{y}=2617$ посл $\mathrm{x}=963 \mathrm{~cm}^{-1}$ & $y=1635 \pm 733, x=963 \mathrm{~cm}^{-1}$ \\
\hline $\begin{array}{l}\text { Enamel after the course of rem. gel } \\
\text { with nano-HAP }\end{array}$ & $y=350 л ь$ пос $x=963$ см$^{-1}$ & $y=1526 \pm 782, x=963 \mathrm{~cm}^{-1}$ & $y=584 \pm 335, x=963 \mathrm{~cm}^{-1}$ \\
\hline Enamel after rinsing course & $y=593 \pm 46, x=963 \mathrm{~cm}^{-1}$ & $\mathrm{y}=1214 \pm 370, \mathrm{x}=963 \mathrm{~cm}^{-1}$ & $y=838 \pm 263, x=963 \mathrm{~cm}^{-1}$ \\
\hline Enamel - control & $y=321 \pm 249, x=963 \mathrm{~cm}^{-1}$ & $y=340 \pm 254, x=963 \mathrm{~cm}^{-1}$ & $y=311 \pm 275, x=963 \mathrm{~cm}^{-1}$ \\
\hline
\end{tabular}

Thus, based on the use of Raman fluorescent technology for assessing the degree of mineralization of hard tooth tissues when using various demineralizing drugs, it is shown that they are all quite effective, the duration of the demineralizing effect is preserved after 14 days of observation. The most effective demineralizing drug, as shown by our research, is gel, paste, rinse, suspension, respectively, in decreasing order of activity. From the figure it follows that when using a gel, containing Nano-HAP in complex with soluble calcium, enamel mineralization is increased by $336 \%$; pastes containing Nano-HAP (Ca, Mg, Zn) - by $225 \%$; rinse and suspension with Nano-HAP (Ca, Mg, Zn) in both cases increased by $104 \%$ (in all cases compared with baseline mineralization of test objects).

In the control group indicators remained practically stable. The final systematized results are presented in the table. Thus, it was revealed that the course of remineralization therapy for 21 days with various demineralizing preparations containing Nano-
HAP (Ca, Mg, Zn) significantly increases the intensity of the Raman hydroxyapatite line $(p=0.040)$ on all test objects (i.e. an increase in the concentration of hydroxyapatite in tooth enamel), except for the control group. The best indicators of demineralizing therapy for 21 days we obtained from a gel containing Nano-HAP in complex with soluble calcium, and a paste containing Nano-HAP (Ca, Mg, $\mathrm{Zn}$ ). After the test objects were held for a month in deionized water, the intensity of the Raman peak decreased, but did not reach the initial limit.

\section{Conclusion}

Thus, on the basis of the conducted research of the study of the demineralizing efficacy various preparations with the use of the Raman method it is shown that all of them are quite effective, while the duration of the demineralizing effect lasts more than 14 days. Most effective demineralizing drugs as shown by our studies on the degree of activity are gel, containing Nano-HAP in complex 
with soluble calcium paste containing Nano-HAP ( $\mathrm{Ca}, \mathrm{Mg}, \mathrm{Zn}$ ), rinse and suspension with Nano-HAP (Ca, Mg, Zn), in descending order. Received data indicate that Raman technologies allow express, online, "In place" assessment of the degree of mineralization hard tissues of the tooth, and also to conduct a selection and comparative evaluation of various modern demineralizing drugs.

\section{Acknowledgement}

None.

\section{Conflict of Interest}

The authors declare no conflict of interests.

\section{References}

1. Ramakrishna R, Rehman G, Basavaraj S, Al Kharafi AA, Durgesh BH, et al. (2015) Applications of Raman Spectroscopy in Den-. tistry: Analysis of Tooth Structure. Applied Spectroscopy Reviews 50(4): 332-50.

2. Tramline P, Bonnet B, Sabatier R, Maury L (2001) A method of age estimation using Raman micro spectrometry imaging of the human dentin. Forensic Sci Int 118(1): 1-9.

3. Penel G, Leroy G, Rey C, Bres E (1998) Micro-Raman spectral study of the $\mathrm{PO} 4$ and $\mathrm{CO} 3$ vibrational modes in synthetic and biological apatites. Calcif Tissue Int 63(6): 475-481.

4. Miyazaki M, Onose H, Moore BA (2002) Analysis of the dentin-resin interface by use of laser Raman spectroscopy. Dent Mater 18(8): 576580 .
5. Ko ACT, Hewko M, Sowa MG, Dong CC, Cleghorn B, et al. (2008) Early dental caries detection using a fibre-optic coupled polarization-resolved Raman spectroscopic system. Opt Express 16 (9): 6274-6284.

6. Ko ACT, Lin Ping Choo Smith, Hewko M, Sowa MG, et al. (2006) Detection of early dental caries using polarized Raman spectroscopy 14(1): 203215

7. Yang S, Li B, Akkus A, Akkus O, Lang L (2014) Wide-Field Raman Imaging of Dental Lesions. Analyst 139(12): 3107-3114.

8. Ionita I (2009) Diagnosis of tooth decay using polarized micro-Raman confocal spectroscopy. Romanian Reports in Physics, Vol. 61(3) 567-574.

9. Timchenko EV, Tichenor PE, Volova LT, Rosenbaum A Yu, Kulikov A Yu J (2016) Analysis of tooth tissues using Raman spectroscopy. Journal of Physics: Conference Series 769(1)

10. Penel G, Delfosse C, Descamps M, Leroy G (2005) Composition of bone and apatite biomaterials as revealed by intravital Raman microspectroscopy. Bone 36 (5): 893-901.

11. Maasai Z, Rehman S, Rehman IU (2008) Fourier transform infrared (FTIR) spec- uroscopy of biological tissues. Appl. Spectro's. Rev 43: 13479.

12. Boskey AL, Mendelsohn R (2005) Infrared spectroscopic characterization of mineralized tissues. Vib Spectro's 38(1-2): 107-14.

13. Krafft C, Sergo V (2006) Biomedical applications of Raman and infrared spectroscopy to diagnose tissues. Journal of Spectroscopy 20(5-6): 195218. 